\title{
Comparison of RF and Pulsed Magnetron Sputtering for the Deposition of AZO Thin Films on PET
}

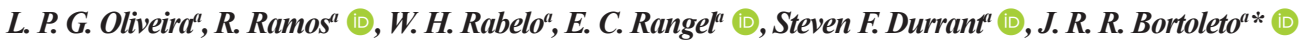 \\ ${ }^{a}$ Universidade Estadual Paulista (UNESP), Instituto de Ciência e Tecnologia de Sorocaba (ICTS), \\ Av. Três de Março 511, Alto de Boa Vista, 18087-180, Sorocaba, SP, Brasil
}

Received: November 22, 2019; Revised: May 22, 2020; Accepted: May 27, 2020

\begin{abstract}
AZO thin films (around $200 \mathrm{~nm}$ thick) were grown on polyethylene terephthalate (PET) at room temperature. The plasma was activated using a $13.56 \mathrm{MHz}(\mathrm{RF})$ or a $15 \mathrm{kHz}$ pulsed (PMS) source at a power of $60 \mathrm{~W}$. Optical reflection and transmittance were measured using a UV-Vis-NIR spectrometer over the wavelengths from $190 \mathrm{~nm}$ to $2500 \mathrm{~nm}$. All samples show average transmittances greater than $83 \%$ in the visible region. The electrical resistivity was measured by the linear four-point probe method to be around $0.001 \Omega \mathrm{cm}$ for $200 \mathrm{~nm}$-thick AZO films grown by PMS. XRD results indicated that the films had a hexagonal wurtzite structure and were preferentially oriented in the (002) plane. The surface morphology of the AZO thin films was characterized using Scanning Electron Microscopy (SEM); film chemical composition was studied using Energy Dispersive X-ray Spectroscopy (EDS). For this, an EDS coupled to the Scanning Electron Microscope was used. Only for films grown by PMS were no cracks observed.
\end{abstract}

Keywords: TCO, zinc oxide, PET, magnetron sputtering.

\section{Introduction}

Films of Transparent Conducting Oxide (TCO) have been used, amongst others, as transparent electrodes, in photovoltaic cells, light-emitting films, and intelligent windows ${ }^{1-4}$. Nowadays, the most used TCO is Indium Tin Oxide (ITO). This material, however, is expensive to produce owing to the relatively low abundance of In in the Earth's crust. Moreover, In is a toxic element, which restricts its use in the usual plasma processes used to produce electronic devices.

Consequently, alternative TCOs are being sought that could substitute ITO, especially in technologies that require large quantities of material, for example, in photovoltaic cells. Thus, zinc oxide doped with $\mathrm{Al}$ (AZO) is a promising TCO because of its distinct characteristics, such as being a naturally abundant, non-toxic, element, with a low production cost, and being compatible with chemical and physical processing for the production of opto-electronic devices. Regarding its electrical properties, new forms of synthesis have been studied to obtain AZO films as conductive as ITO, while maintaining its optical transparency above $80 \%$ in the visible region.

Recently, the use of polymeric substrates for the fabrication of light-emitting devices ${ }^{5}$ and even of photovoltaic cells ${ }^{6}$ has been consolidating scientifically and industrially. Diverse flexible polymers, such as polyamide, have been studied as substrates for the fabrication of opto-electronic devices. Polyethylene Terephthalate (PET) has received considerable attention for several reasons. First, compared to polyamide (PI), PET has greater optical transparency and mechanical resistance, and lower fabrication cost. Second, PET recycled

*email: jose.rr.bortoleto@unesp.br from food packaging may be used, further reducing the production cost and contributing to environmental preservation.

Diverse methods such as sol-gel, thermal vaporization, PLD and magnetron sputtering have been employed to synthesize TCOs. In these deposition methods ${ }^{7,8}$, desired resistivities were observed for TCOs, but required the use of temperatures greater than RT (room temperature). Owing to the degradation of the polymeric matrix above the melting point (for example, $80^{\circ} \mathrm{C}$ for $\mathrm{PET}$ and $250^{\circ} \mathrm{C}$ for polyamide), or by collisions with energetic species, however, there are some limitations on the choice of synthesis parameters of TCO. Thus, the synthesis of TCO films on polymeric substrates requires process parameters that do not degrade the substrate, allow good adhesion, generate little film/substrate stress, and yet maintain the desired optical and electrical properties ${ }^{9-13}$.

In this context, magnetron sputtering, in addition to excellent reproducibility and low production cost in large scale, also allows the synthesis of thin films while maintaining the substrate at room temperature ${ }^{14-16}$. Even in this case, however, the deposition parameters must be finely adjusted to obtain a transparent, electrically conducting film, well-adhered to the substrate. As observed in several studies ${ }^{17-19}$, devices containing TCO films combined with flexible substrates can be obtained by exploiting the advantages of sputtering already mentioned.

According to Shen et al. ${ }^{10}$ and Koidis et al. ${ }^{20}$, AZO/PET films present an electrical resistivity of $10^{-3} \Omega \mathrm{cm}$ when using higher plasma powers. However, there was a reduction in optical transparency caused mainly by the breaking of chemical bonds of the PET produced by the collision of energetic particles produced in the plasma. Other important aspects are the production of cracks and low adhesion to the 
substrate. Cracks may be generated by factors such as high deposition rates or collisions with energetic particles during the deposition as well as mechanical stress or morphological structures of the deposited film. In turn, according to Fortunato et al. ${ }^{21}$, cracks cause a reduction in the electrical conductivity of the TCO film.

For these reasons, the power applied to the plasma and the type of power supply are crucial factors for the successful deposition of AZO on polymeric substrates or organic devices by magnetron sputtering. Indeed, Lin et al. ${ }^{22}$ reported that the electrical resistivity of ITO/PES films remained at $1 \times 10^{-3} \Omega \mathrm{cm}$ even at low deposition powers when using a pulsed supply. The same behavior does not occur with films produced using a RF supply.

Hence this work compares the synthesis of AZO films on PET by magnetron sputtering at room temperature, using a RF supply (13.56 MHz) and a pulsed supply of frequency $15 \mathrm{kHz}$ (PMS). In addition, the formation of cracks and the electrical stability with ageing were assessed for AZO films of different thicknesses deposited on PET.

Several TCO's require high deposition temperatures, which makes their application onto polymeric substrates unfeasible ${ }^{23}$. The results of the present study could help solve this problem. Deposition on polymeric substrates could expand the possibilities of new technologies such as Flexible Electronic Devices (FEDs), organic photovoltaics, organic light-emitting diodes, etc ${ }^{20}$. Also, it could facilitate the production and optimize the cost on an industrial scale by using roll-to-roll manufacturing methods ${ }^{24}$.

\section{Experimental}

Rectangular PET substrates, $35 \mathrm{~mm}$ x $25 \mathrm{~mm}$, and $0.1 \mathrm{~mm}$ thickness were used. For $10 \mathrm{~min}$. for each stage, substrates were cleaned in an ultrasonic bath of distilled water, and then washed in isopropanol. A conductive AZO ( $\mathrm{ZnO}$ with 2 wt. $\%$ of $\mathrm{Al}_{2} \mathrm{O}_{3} 99.9 \%$ ) target of 3 inches diameter was used. Film deposition was undertaken using RF (13.56 MHz) and a pulsed supply $(15 \mathrm{kHz})$. The target-sample distance $\left(\mathrm{d}_{\mathrm{T}-\mathrm{S}}\right)$ was 4 and $5 \mathrm{~cm}$. In both cases, the argon pressure was fixed at $3 \mathrm{mTorr}$ and the power maintained at $60 \mathrm{~W}$ for $30 \mathrm{~min}$.

The thickness of the AZO/PET films was measured using a DEKTAK 150 profilometer. Electrical properties were determined using the linear four-point method. The optical transmittance and reflectance measurements were made using a Perkin Elmer Uv-Vis-NIR Lambda 750 Spectrometer over the wavelength range of 190 to $2700 \mathrm{~nm}$. The chemical composition of the films was estimated using EDS with an accessory attached to a JSM-6010LA Scanning Electron Microscope. The density of cracks at the microscale in the films was also assessed using EDS.

Structural properties were analyzed using X-ray diffraction with a Panalytical X'Pert Powder diffractometer using $\mathrm{Cu}$ $\mathrm{K}_{\alpha}$ radiation at a step-rate of $0.02\left(^{\circ}\right)$, an integration time of
$6 \mathrm{~s}$, and scan from 20 to $80^{\circ}$ in grazing angle incidence $\left(2^{\circ}\right)$. Crystallite grain size (D) was estimated using the Scherrer equation $^{25}$

$$
D=0.9 \lambda / \beta \cdot \cos (\theta)
$$

where $\lambda=0.154056 \mathrm{~nm}, \beta$ and $\theta$ are experimental values of the FWHM and (002) peak position of spectra of AZO films. The residual tension (stress) in the AZO/PET films was also assessed using the following equation ${ }^{26}$ :

$$
\varepsilon=\left(C_{\text {film }}-C_{\text {bulk }}\right) / C_{\text {bulk }}
$$

where $C_{\text {film }}$ is the lattice parameter obtained from the diffractogram of the synthesized film and $C_{b u l k}$ is the lattice parameter of bulk $\mathrm{ZnO}$.

\section{Results and Discussion}

Table 1 presents the thickness, mean optical transmittance in the 400 to $700 \mathrm{~nm}$ wavelength range and electrical resistivity of the AZO/PET films as a function of the type of supply (RF and PMS) and different target-substrate distances. The optical transmittance of the AZO/PET was greater than $80 \%$, independent of the deposition parameters. Film electrical resistivity was around $10^{-2} \Omega \mathrm{cm}$ with the RF supply and $10^{-3} \Omega \mathrm{cm}$ with PMS. The decrease in resistivity obtained using a PMS power supply is caused by the absence of cracks (that is revealed by SEM) and to the high concentration of carbon (as revealed by EDS) compared to that of films deposited using RF. In addition, the electrical resistivity increased as the target-substrate distance increased from $4 \mathrm{~cm}$ to $5 \mathrm{~cm}$.

Figure 1 shows the transmittance and reflectance spectra of the PET substrate and the AZO/PET films described in Table 1. Above $1250 \mathrm{~nm}$, the transmittance spectra exhibit a

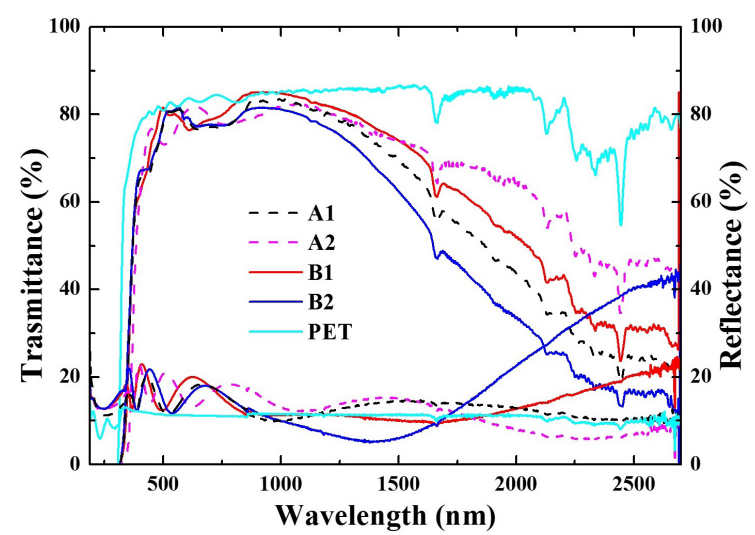

Figure 1. Optical transmittance and reflectance spectra of the PET substrate and the AZO/PET samples described in Table 1.

Table 1. Type of supply, target-substrate distance, thickness, optical transmittance and electrical resistivity of the samples studied.

\begin{tabular}{cccccc}
\hline Sample & Supply & $\mathrm{d}_{\mathrm{T}-\mathrm{S}}(\mathrm{cm})$ & $\mathrm{t}(\mathrm{nm})$ & $\mathrm{T}(\%)$ & $\rho(m \Omega . \mathrm{cm})$ \\
\hline $\mathrm{A} 1$ & $\mathrm{RF}$ & 5 & 260 & 80 & 38 \\
\hline $\mathrm{A} 2$ & $\mathrm{RF}$ & 4 & 272 & 80 & 17 \\
\hline B1 & PMS & 5 & 193 & 81 & 7.0 \\
\hline B2 & PMS & 4 & 250 & 83 & 2.5 \\
\hline
\end{tabular}


reduction typical of TCOs. Below $370 \mathrm{~nm}$ there is absorption owing to interband transitions in AZO. In the visible region, the transmittance remains $\sim 80 \%$, while the optical reflectance is around $15 \%$. Interference fringes are present. Compared with the PET spectra, note that AZO is almost transparent in this region of the spectrum. These films have greater transmittances than similar films on polymeric substrates reported in the literature ${ }^{4,10,27}$.

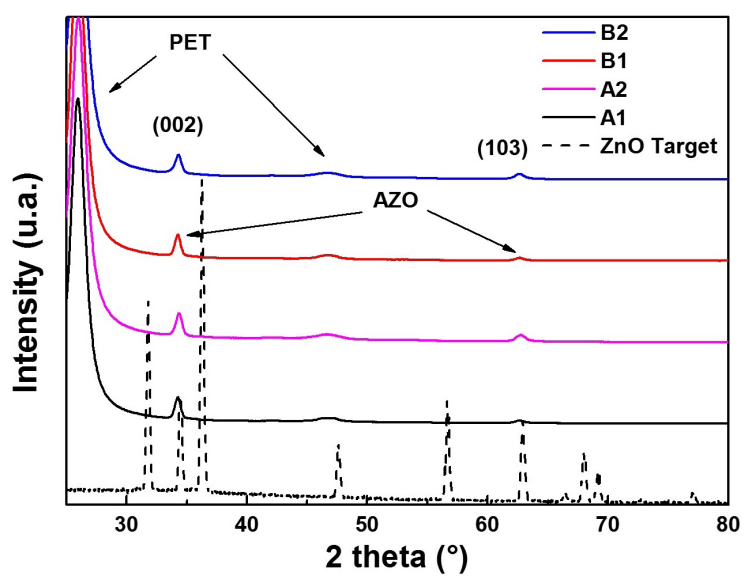

Figure 2. X-ray diffractogram of bulk $\mathrm{ZnO}$ bulk and of the AZO films deposited on PET. The arrows indicate the DRX peaks of the PET substrate and the (002) and (103) planes of the AZO films.
Figure 2 shows X-ray diffractogram of the AZO/PET films described in Table 1. For reference, the diffractogram of bulk $\mathrm{ZnO}$ is also shown. The peaks at $25.88^{\circ}$ and $48^{\circ}$ are related to the PET substrate, as indicated in earlier work ${ }^{4,12,24}$. The peaks near $34^{\circ}$ and $62^{\circ}$ refer to the (002) and (103) of the AZO film, respectively. Note that all the films are polycrystalline, having a hexagonal wurtzite structure typical of $\mathrm{ZnO}$ films ${ }^{28,29}$. Moreover, the presence of the prominent peak related to the (002) plane, indicates that the films have a preferential orientation in this direction, as also observed in the literature ${ }^{12,23,30}$.

Table 2 shows the angular values $(2 \theta)$ and the FWHM $(\beta)$ of the (002) peaks of the spectra of the AZO films, as well as the estimated values of the crystallite size (D) and the residual tension $(\varepsilon)$ of the film/substrate. The data indicate that the PMS process reduces slightly the crystallite size. For all the samples, the residual tension is considerably reduced from -1.01 to -0.48 for sample A1 and B2. The negative values indicate compressive stress. This reduction may be related to the absence of cracks in the film deposited by PMS, as revealed by MEV/EDS analyses to be discussed below.

Figure 3 shows scanning electron micrographs, taken in secondary electron mode, of the surfaces of the AZO/PET films. The formation of cracks is visible in the films produced by RF, especially for the target-substrate distance of $4 \mathrm{~cm}$. For the films produced by PMS, no cracks are visible, at least on the same scale. Figure 4 a shows a micrograph of sample A2 marked with the three positions where EDS
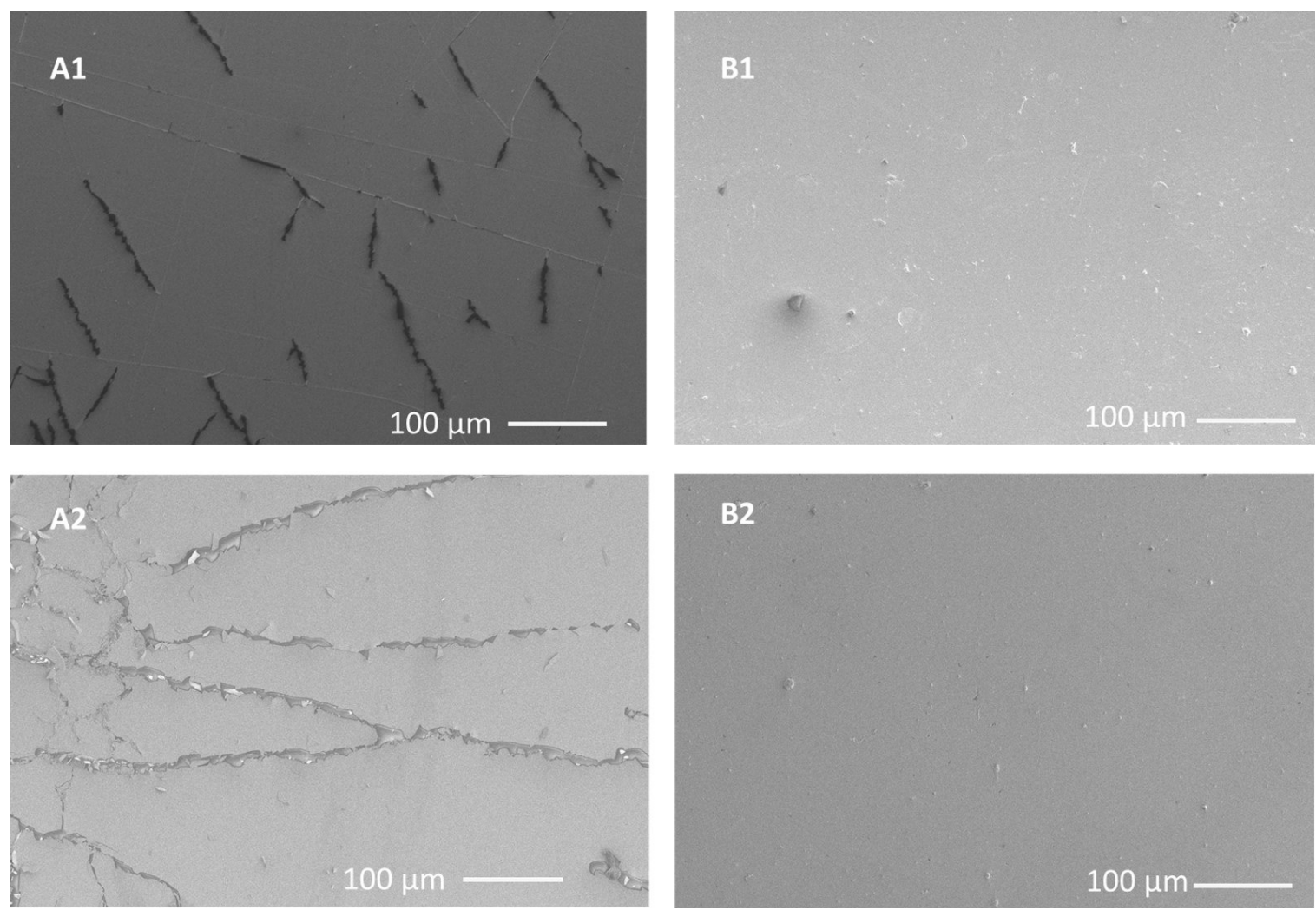

\section{B2}

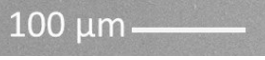

Figure 3. Micrographs (obtained by SEM) of AZO/PET films deposited by RF and PMS, with target-substrate distances of 5 and $4 \mathrm{~cm}$. For the films deposited using RF, the presence of cracks is evident, which affects the adhesion to the substrate and the electrical conductivity of the AZO film. 


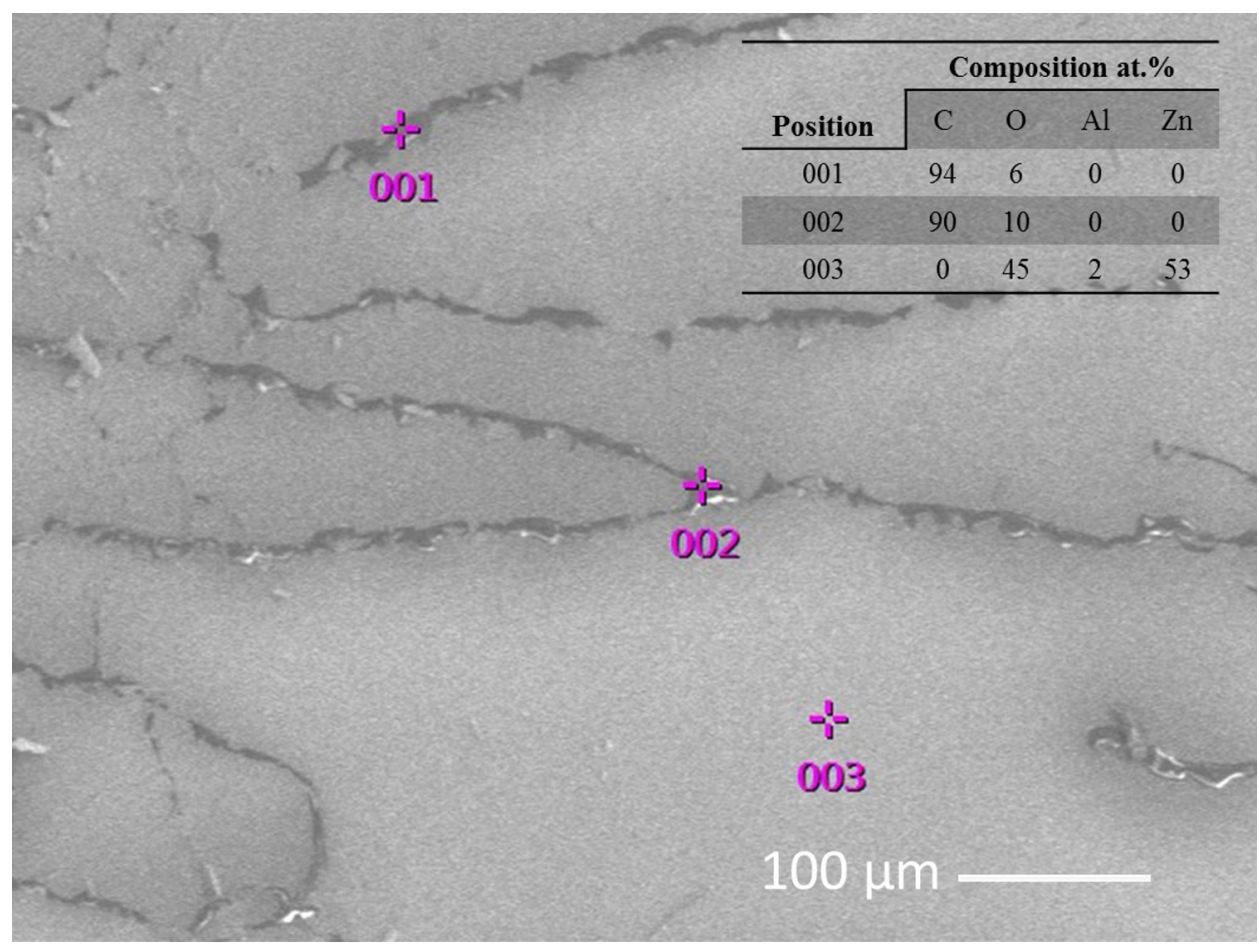

Figure 4. Scanning electron micrograph of the AZO/PET films deposited by RF (sample A2). Three positions are indicated where EDS measurements were made. The 001 and 002 positions, which are above cracks, exhibit high concentrations of C, owing to the PET substrate. In contrast, at position 003 only $\mathrm{Zn}, \mathrm{O}$ and $\mathrm{Al}$, which originate form AZO, are detected.

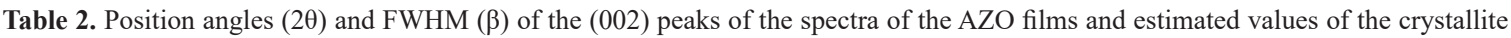
size (D) and the residual tension ( $\varepsilon$ ) of the film/substrate. The $2 \theta$ angle of the (002) peak and the FWHM of bulk ZnO bulk were $34.48^{\circ}$ and $0.32^{\circ}$, respectively.

\begin{tabular}{ccccc}
\hline Sample & $2 \theta\left(^{\circ}\right)$ & FWHM $\left(^{\circ}\right)$ & D $(\mathrm{nm})$ & $\varepsilon$ \\
\hline A1 & $34.26 \pm 1.2 \times 10^{-3}$ & $0.55 \pm 4.4 \times 10^{-3}$ & $15.1 \pm 9.8 \times 10^{-5}$ & $-1.01 \pm 3.3 \times 10^{-2}$ \\
\hline A2 & $34.26 \pm 1.3 \times 10^{-3}$ & $0.55 \pm 4.5 \times 10^{-3}$ & $15.2 \pm 9.9 \times 10^{-5}$ & $-1.01 \pm 3.2 \times 10^{-2}$ \\
\hline B1 & $34.28 \pm 4.5 \times 10^{-3}$ & $0.61 \pm 15 \times 10^{-3}$ & $13.6 \pm 3.2 \times 10^{-4}$ & $-0.81 \pm 6.5 \times 10^{-2}$ \\
\hline B2 & $34.35 \pm 2.5 \times 10^{-3}$ & $0.59 \pm 8.5 \times 10^{-3}$ & $14.1 \pm 1.8 \times 10^{-4}$ & $-0.48 \pm 1.6 \times 10^{-2}$ \\
\hline
\end{tabular}

measurements were made. The 001 and 002 positions are above cracks, while position 003 is above a homogeneous region of the film.

Figure $4 \mathrm{~b}$ shows that the 001 and 002 positions exhibit a high carbon concentration, which derives from the PET substrate. This shows that in the cracks, the film is completely separate, revealing the polymeric substrate and causing an increase in the electrical resistance of the AZO film.

At the 003 position, only $\mathrm{Zn}, \mathrm{Al}$ and $\mathrm{O}$ are revealed, which are characteristic of the AZO. Furthermore, the composition of the AZO film is compatible with the EDS values (at.\%) for the ceramic target: $\mathrm{Zn}=55.0, \mathrm{Al}=1.7$ and $\mathrm{O}=43.3$. There are slight increases in the concentrations of $\mathrm{O}$ and $\mathrm{Al}$, which are consistent with their greater bond energies ${ }^{31-33}$.

Such results also indicate that EDS measurements may be used to quantify the presence of cracks, via de C concentration. For this, EDS area analyses were carried out with an electron beam over a typical area of $1 \mathrm{~mm} \times 1 \mathrm{~mm}$. The data obtained are shown in Table 3. From Figure 4, the $\mathrm{C}$ concentration represents an estimate of the crack density (more precisely the area of the exposed substrate) along the AZO film.

The films synthesized by PMS present a much lower density of cracks than films produced using RF. Indeed, the EDS data indicate that sample B2 is free of cracks. Moreover, this film has an optical transmittance of $83 \%$, an electrical resistivity of $2.5 \times 10^{-3} \Omega \mathrm{cm}$, and the lowest estimated residual tension $(-0.48)$. Thus it may be concluded that the PMS synthesis at a target-substrate distance of $4 \mathrm{~cm}$ produced superior AZO/PET films both in electrical properties and in film/substrate adhesion.

Our result shows an advance in comparison with those presented by Tsay and $\mathrm{Pai}^{34}$ who found a resistivity of $3.7 \times 10^{-2} \Omega \mathrm{cm}$ using a deposition temperature of $135^{\circ} \mathrm{C}$.

To investigate the stability of the films upon ageing, films were deposited using PMS under the same conditions as those used for sample $\mathrm{B} 2\left(\mathrm{P}=60 \mathrm{~W}, \mathrm{~d}_{\mathrm{T}-\mathrm{S}}=4 \mathrm{~cm}\right.$ at room temperature) for deposition times of $5 \mathrm{~min}$ (B3) and $30 \mathrm{~min}$ (B4). The film thicknesses, measured using profilometry, were $51 \pm 3 \mathrm{~nm}$ and $200 \pm 10 \mathrm{~nm}$, respectively. Figure 5 represents the optical transmittance and reflectance spectra 
Table 3. EDS area measurements over an area of $1 \mathrm{~mm} \times 1 \mathrm{~mm}$ of the AZO/PET films. From Figure 4, the C concentration represents an estimate of the density of cracks along the AZO film.

\begin{tabular}{ccccc}
\hline \multicolumn{5}{c}{ Composition (at.\%) $\pm 3 \%$} \\
\hline Sample & $\mathrm{C}$ & $\mathrm{O}$ & $\mathrm{Al}$ & $\mathrm{Zn}$ \\
\hline $\mathrm{A} 1$ & 10.9 & 42.6 & 1.4 & 46.2 \\
\hline $\mathrm{A} 2$ & 22.8 & 38.9 & 1.2 & 43.8 \\
\hline $\mathrm{B} 1$ & 2.2 & 44 & 1.5 & 52.3 \\
\hline B2 & 0 & 44.9 & 1.6 & 52.4 \\
\hline
\end{tabular}

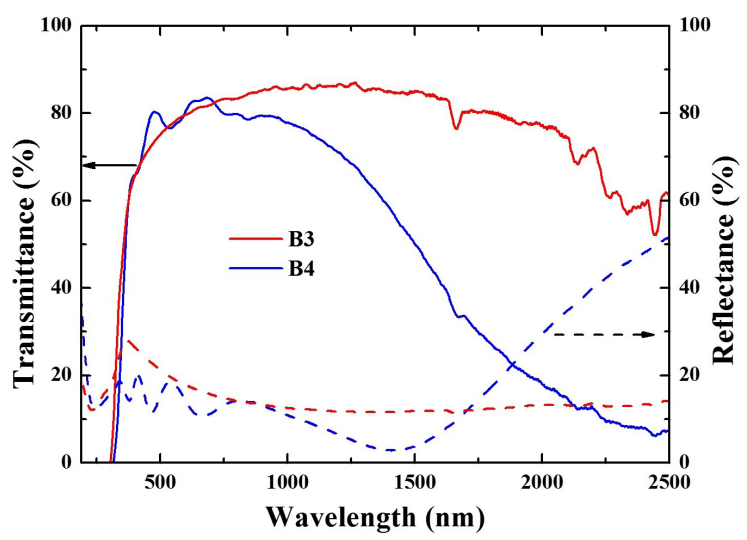

Figure 5. Transmittance and reflectance spectra of AZO/PET films deposited under the conditions of sample B2 (PMS and $\mathrm{d}_{\mathrm{T}-\mathrm{S}}=4 \mathrm{~cm}$ ) for $5 \mathrm{~min}$ (B3) and $30 \mathrm{~min}(\mathrm{~B} 4)$.

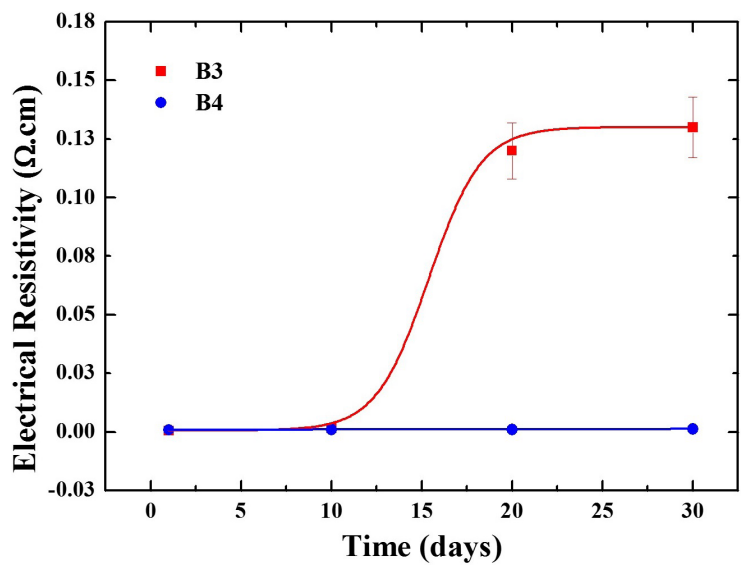

Figure 6. Electrical resistivity of the AZO films obtained using PMS as a function of ageing time.

of the AZO/PET films. In the visible region, the AZO film does not absorb, showing a slight reduction in transparency owing to interference effects produced by the difference in refractive index between AZO $(\sim 2.0)$ and PET $(\sim 1.58)$.

Figure 6 shows electrical resistivity as a function of ageing time for the samples under ambient conditions. According to some growth models ${ }^{35}$, the film deposited for $5 \mathrm{~min}$ has smaller crystallites compared to the films deposited for $30 \mathrm{~min}$. This greater number of the grain edges contributes to electron scattering, decreasing their mobility and consequently increasing resistivity. As for ageing, with a greater number of grain edges, there will be a more pronounced incorporation of oxygen, increasing the oxidation rate and therefore the resistivity.

Both samples show an electrical resistivity immediately after deposition of less than $8.0 \times 10^{-4} \Omega \mathrm{cm}$. Despite this, the thinnest film $(50 \mathrm{~nm})$, showed an increase in resistivity in a few days, stabilizing at $\mathrm{t} 1.3 \times 10^{-2} \Omega \mathrm{cm}$. The film of $200 \mathrm{~nm}$ presented a slight increase, stabilizing at $1.2 \times 10^{-3} \Omega \mathrm{cm}$, compatible with the value obtained for sample B2. This indicates that above a certain critical thickness the films are electrically stable. Below this value, the electrical properties suffer degradation, possibly because of the reaction of $\mathrm{Al}$ atoms with oxygen that diffuses into the AZO film while the morphological structure is at the nucleation stage ${ }^{36}$.

\section{Conclusions}

This study compared AZO/PET films deposited by magnetron sputtering at ambient temperature, using different plasma power supplies: RF (13.56 MHz) and pulsed at a frequency of $15 \mathrm{kHz}$ (PMS). In addition, the formation of cracks was evaluated together with the electrical stability with ageing.

All of the AZO/PET samples present optical transmittances greater than $80 \%$ in the visible region. Morphological analysis revealed that all the films are polycrystalline and exhibit a wurtzite structure with preferential growth in the crystallographic direction of the (002) plane. The films produced using RF, however, show greater residual tensions, which contribute to the formation of cracks in the AZO film.

A greater density of cracks was observed for the AZO films deposited by PMS. Regarding the electrical resistivity, the AZO films synthesized by RF possess values above $1.0 \times 10^{-2} \Omega \mathrm{cm}$, while the films produced using PMS have values of about $1.0 \times 10^{-3} \Omega \mathrm{cm}$.

Finally, the film that gave the best performance was that deposited at a target-substrate distance of $4 \mathrm{~cm}$, using the PMS source, for $30 \mathrm{~min}$. Under this condition the film had a resistivity of $1.0 \times 10^{-3} \Omega \mathrm{cm}$, a transmittance of $\sim 83 \%$, presented no cracks and exhibited good stability in its properties upon ageing.

Therefore, PMS shows itself to be more adequate for the production of AZO films on PET, with potential application in the fabrication of cheap, flexible opto-electronic devices.

\section{Acknowledgements}

The authors thank the Brazilian agencies $\mathrm{CNPq}$ (555774/2010-4, 301622/2012-4) and FAPESP (2017/15853-0) for financial support. Two of us (RR and LP) thank CAPES for study grants (1754231/2017 and 1795290/2018). This research was also supported in part by CAPES, code 001.

\section{References}

1. Ghorannevis Z, Akbarnejad E, Salar Elahi A, Ghoranneviss M. Application of RF magnetron sputtering for growth of AZO on glass substrate. J Cryst Growth. 2016;447:62-6.

2. Tseng CH, Huang CH, Chang HC, Chen DY, Chou CP, Hsu CY. Structural and optoelectronic properties of Al-doped zinc oxide films deposited on flexible substrates by radio frequency magnetron sputtering. Thin Solid Films. 2011;519:7959-65. 
3. Rahmane S, Aida MS, Djouadi MA, Barreau N. Effects of thickness variation on properties of $\mathrm{ZnO}$ :Al thin films grown by RF magnetron sputtering deposition. Superlattices Microstruct. 2015;79:148-55

4. Akin N, Ceren Baskose U, Kinaci B, Cakmak M, Ozcelik S. AZO thin film-based UV sensors: effects of RF power on the films. Appl Phys, A Mater Sci Process. 2015;119:965-70.

5. Lewis J. Material challenge for flexible organic devices. Mater Today. 2006;9:38-45.

6. Sun N, Fang G, Qin P, Zheng Q, Wang M, Fan X, et al. Efficient flexible organic solar cells with room temperature sputtered and highly conductive $\mathrm{NiO}$ as hole-transporting layer. J Phys D Appl Phys. 2010; 43(44):445101.

7. Liu R, Chen Y, Ding S, Li Y, Tian Y. Preparation of highly transparent conductive aluminum-doped zinc oxide thin films using a low-temperature aqueous solution process for thin-film solar cells applications. Sol Energy Mater Sol Cells. 2019;203:110161.

8. Deva Arun Kumar K, Ganesh V, Shkir M, AlFaify S, Valanarasu S. Effect of different solvents on the key structural, optical and electronic properties of sol-gel dip coated AZO nanostructured thin films for optoelectronic applications. J Mater Sci Mater Electron. 2018;29:887-97.

9. Park SU, Koh JH. Low temperature rf-sputtered in and $\mathrm{Al}$ co-doped $\mathrm{ZnO}$ thin films deposited on flexible PET substrate. Ceram Int. 2014;40:10021-5.

10. Shen H, Zhang H, Lu L, Jiang F, Yang C. Preparation and properties of AZO thin films on different substrates. Progress in Natural Science: Materials International. 2010;20:44-8.

11. Pei ZL, Zhang XB, Zhang GP, Gong J, Sun C, Huang RF, et al. Transparent conductive $\mathrm{ZnO}$ :Al thin films deposited on flexible substrates prepared by direct current magnetron sputtering. Thin Solid Films. 2006;497:20-3.

12. Fernández S, Naranjo FB. Optimization of aluminum-doped zinc oxide films deposited at low temperature by radio-frequency sputtering on flexible substrates for solar cell applications. Sol Energy Mater Sol Cells. 2010;94:157-63.

13. Lu JG, Ye ZZ, Zeng YJ, Zhu LP, Wang L, Yuan J, et al. Structural, optical, and electrical properties of (Zn,Al)O films over a wide range of compositions. J Appl Phys. 2006;100(7):073714073714-11.

14. Ellmer K. Magnetron sputtering of transparent conductive zinc oxide relation between the sputtering and the electronic properties. J Phys D Appl Phys. 2000;33:17-32.

15. Rahmane S, Djouadi MA, Aida MS, Barreau N, Abdallah B, Hadj Zoubir N. Power and pressure effects upon magnetron sputtered aluminum doped $\mathrm{ZnO}$ films properties. Thin Solid Films. 2010;519:5-10.

16. Ellmer K, Wendt R. Dc. And r.f. (reactive) magnetron sputtering of $\mathrm{ZnO}$ :Al films from metallic and ceramic targets: a comparative study. Surf Coat Tech. 1997;93:21-6.

17. Lee SJ, Kim S, Lim DC, Kim DH, Nahm S, Han SH. Inverted bulk-heterojunction polymer solar cells using a sputter-deposited Al-doped $\mathrm{ZnO}$ electron transport layer. J Alloys Compd. 2019;777:717-22.

18. Mbule P, Wang D, Grieseler R, Schaaf P, Muhsin B, Hoppe $\mathrm{H}$, et al. Aluminum-doped $\mathrm{ZnO}$ thin films deposited on flat and nanostructured glass substrates: quality and performance for applications in organic solar cells. Sol Energy. 2018;172:21924.

19. Shen X, Yang M, Zhang C, Qiao Z, Wang H, Tang C. Utilizing magnetron sputtered AZO-ITO bilayer structure as transparent conducting oxide for improving the performance of flexible CIGS solar cell. Superlattices Microstruct. 2018;123:251-6.

20. Koidis C, Logothetidis S, Kassavetis S, Laskarakis A, Hastas NA, Valassiades O. Growth mechanisms and thickness effect on the properties of Al-doped $\mathrm{ZnO}$ thin films grown on polymeric substrates. Physica Status Solidi Applications and Materials Science. 2010;207:1581-5.

21. Fortunato E, Nunes P, Marques A, Costa D, Aguas H, Ferreira I, et al. Transparent, conductive $\mathrm{ZnO}:$ al thin film deposited on polymer substrates by RF magnetron sputtering. Adv Eng Mater. 2002;152:247-51.

22. Lin YC, Li JY, Yen WT. Low temperature ITO thin film deposition on PES substrate using pulse magnetron sputtering. Appl Surf Sci. 2007;254:3262-8.

23. Girtan M, Vlad A, Mallet R, Bodea MA, Pedarnig JD, Stanculescu A, et al. On the properties of aluminium doped zinc oxide thin films deposited on plastic substrates from ceramic targets. Appl Surf Sci. 2013;274:306-13.

24. Jeong JA, Shin HS, Choi KH, Kim HK. Flexible Al-doped ZnO films grown on PET substrates using linear facing target sputtering for flexible OLEDs. J Phys D Appl Phys. 2010;43(46):465403.

25. Tseng CA, Lin JC, Chang YF, Der Chyou S, Peng KC. Microstructure and characterization of Al-doped $\mathrm{ZnO}$ films prepared by RF power sputtering on $\mathrm{Al}$ and $\mathrm{ZnO}$ targets. Appl Surf Sci. 2012;258:5996-6002.

26. Rosa AM, Silva EP, Chaves M, Trino LD, Lisboa-Filho PN, Silva TF, et al. Structural transition of $\mathrm{ZnO}$ thin films produced by RF magnetron sputtering at low temperatures. J Mater Sci Mater Electron. 2013;24:3143-8.

27. Silva-lopez HE, Marcelino BS, Guillen-cervantes A, Zelayaangel O, Ramirez-bon R. Physical properties of Sputtered Indium-doped $\mathrm{ZnO}$ films deposited on flexible transparent substrates. Mater Res. 2018;21(6):e20180224.

28. Banerjee AN, Ghosh CK, Chattopadhyay KK, Minoura H, Sarkar AK, Akiba A, et al. Low-temperature deposition of $\mathrm{ZnO}$ thin films on PET and glass substrates by DC-sputtering technique. Thin Solid Films. 2006;496:112-6.

29. Dave PY, Patel KH, Chauhan KV, Chawla AK, Rawal SK. Examination of zinc oxide films prepared by magnetron sputtering. Procedia Technology. 2016;23:328-35.

30. Lee JH. Effects of sputtering pressure and thickness on properties of $\mathrm{ZnO}$ : Al films deposited on polymer substrates. J Electroceram. 2009;23:512-8.

31. Painter GS. Bonding of oxygen on aluminum: relation between energy-band and cluster models. Phys Rev B. 1978;17:2416-29.

32. Ziółkowski J, Dziembaj L. Empirical relationship between individual cation-oxygen bond length and bond energy in crystals and in molecules. J Solid State Chem. 1985;57:291-9.

33. Janotti A, Van De Walle CG. Fundamentals of zinc oxide as a semiconductor. Rep Prog Phys. 2009;72(12):126501.

34. Tsay CY, Pai KC. Properties of Al-Ga co-doped ZnO semiconductor thin films deposited on polyethylene terephthalate substrates by radio frequency magnetron sputtering. Thin Solid Films. 2018;654:11-5.

35. Kluth O, Schöpe G, Hüpkes J, Agashe C, Müller J, Rech B. Modified Thornton model for magnetron sputtered zinc oxide: film structure and etching behaviour. Thin Solid Films. 2003;442:80-5.

36. Jullien M, Horwat D, Manzeh F, Escobar Galindo R, Bauer P, Pierson JF, et al. Influence of the nanoscale structural features on the properties and electronic structure of Al-doped $\mathrm{ZnO}$ thin films: an X-ray absorption study. Sol Energy Mater Sol Cells. 2011;95:2341-6 